\title{
DIGITALIZATION OF CITIES - SMART CITY INTERVENTIONS IN THE CASE OF SARAJEVO
}

\author{
A. Hudović Kljuno ${ }^{1}$, L. Krivošić Dizdarević ${ }^{1}$
}

${ }^{1}$ Architecture Program, Faculty of Engineering and Natural Sciences, International University of Sarajevo, Bosnia and Herzegovina ( ahudovic@ius.edu.ba,dleila@ius.edu.ba )

KEY WORDS: Rapid urbanisation, Climatic change, Improvement of habitat, Sarajevo, Resilience, Smart city technology

\begin{abstract}
:
Many countries in the world are becoming more aware of climatic changes, rising pollution, and running out of resources, predicting their impact on the future of humanity thus giving solutions for slowing down this process. Due to the mass urbanization of our planet, it became highly popular to talk about resilient and smart cities. And while some countries are still on a theoretical level, others, more advanced in their thinking and technical possibilities and with the higher consciousness of the importance of this issue are already putting things into action. European Union gives guidelines on how cities across Europe can improve in the future. There are several good examples of different actions across European countries that make their cities more resilient, more sustainable, and pleasant for living. Contrarily, in the cities of the developing European countries such as Bosnia and Herzegovina, the idea of resilient and Smart cities is still in its infancy. This paper aims to introduce different parameters that make cities more resilient and to show several of the best practices from Europe which use Smart city technologies while questioning the current situation in Sarajevo, the capital of Bosnia and Herzegovina. Authors are introducing potentials of Sarajevo and smaller projects that can be starting points in the process of improvement of habitat climate in this city and its transformation to a smart and sustainable city.
\end{abstract}

\section{INTRODUCTION}

Urbanization (the name comes from Latin word urbus "city") is a term that denotes the natural or mechanical increase of population in urban areas, the expansion of urban areas, or the transformation of predominantly rural characteristics of an area into urban ${ }^{1}$.

The process of urbanization began with the very beginnings of civilization and the creation of cities. It intensified only after the industrial revolution, when machines replaced human labour, especially in agriculture, and the service sector in the economy expanded.

The concept of urbanization includes the spatial expansion of existing and the birth of new cities, the transformation of the general state of urbanization of a country's territory: reducing the number of rural settlements, increasing the number of small, medium, and large urban centres, increasing concentration of central urban functions (financial, production, educational, cultural) in the largest settlements and the spread of the influence of the largest cities on the total territory of a country. The process of leaving the village and moving the population to cities brings with it a whole range of problems, especially when it manifests itself as a sudden concentration of a large number of inhabitants in a relatively small area. Therefore, a special application of special measures and procedures for the purpose of construction and organization of urban settlements is required. Large cities require specially organized traffic, water

\footnotetext{
${ }^{1}$ https://www.oxfordlearnersdictionaries.com/
}

supply, sewerage, food and other groceries, electricity and telecommunications network. In addition, special attention must be paid to the quality of life in the city, including the fight against pollution, crime, and various forms of social pathology. It is estimated that worldwide $55 \%$ of all people live in cities. They cover $4 \%$ of the land surface, use $67 \%$ of all energy that is produced, and are responsible for $70 \%$ of the emission of greenhouse gasses (Van der Bosch, 2017).

It is predicted that by 2050 about $64 \%$ of the developing world and $86 \%$ of the developed world will be urbanized ${ }^{2}$. That is equivalent to approximately 3 billion urbanites by 2050 , much of which will occur in Africa and Asia. As Cohen (Cohen, 2015) of the United Nations suggests nearly all global population growth from 2017 to 2030 will be by cities, with about 1.1 billion new urbanites over the next 10 years.

Although a global process, urbanization is especially intense in underdeveloped countries, where it is taking drastic proportions leading to a sharp increase in population in the largest cities and, consequently, to problems organizing life in them. Unlike underdeveloped countries, the process of urbanization is much more stable in the long-urbanized and economically developed countries of Western Europe and North America (Clark, Moonen, and Nunly, 2018).

In addition to significant economic aspects (job offers in cities), an important driver of urbanization was the desire to participate in the city life, its rituals, but also in the very idea of living in the most developed, most civilized, and most famous parts of

\footnotetext{
2 https://www.unfpa.org/urbanization
} 
the world. At the same time, life in the countryside seemed failed and hopeless.

Almost all urban utopias contain restrictions on the size of settlements (no more than 50,000 inhabitants), believing that this would lead to a better quality of life (Caves, 2004). However, modern urbanization trends have long moved away from Ebenezer Howard's ideal of Garden City and led to the emergence of oversized settlements, metropolitan areas, and megalopolises, in which size, number, and mass have become the basic measure. Today's largest cities have tens of millions of inhabitants, so the emergence of fully urbanized large areas of the Earth, a global city of ecumenopolis ${ }^{3}$, is predicted.

This new city creates very complex urban and socio-cultural directions that discredit and destroy traditional values of the society and create new ones. Under the guise of a Smart city, new urban rules have been born; the creation of the Smart city has evolved with the new order to be applied.

The Smart city concept integrates information and communication technology and various physical devices that are connected to the IoT network to optimize the efficiency of city operations and services and connect to citizens (Anthopoulos, 2019). But what exactly is a Smart city? Although there are many definitions of the Smart city, a commonly understood explanation involves an urban area that uses different types of electronic methods and sensors to collect data that is further used to administer different things efficiently. The data is taken from citizens and devices equality and is analysed and monitored to govern the city's functions such as traffic, transport systems, various utilities, water supply, waste, crime, schools, libraries, and other community services (McLaren and Agyeman, 2015).

As Deakin and Al Waer (Deakin and Al Waer, 2011) conclude four major factors contribute to a definition of a Smart city. They are:

1. The application of a wide range of electronic and digital technologies to communities and cities.

2. The use of ICT to transform life and working environments within the region.

3. The embedding of such Information and Communications Technologies (ICTs) in government systems.

4. The territorialisation of practices that brings ICTs and people together to enhance the innovation and knowledge that they offer.

These given parameters are the base on which cities can and have been improving daily activities and functions for their inhabitants.

\section{CONCEPTS OF THE URBAN RESILIENCE AND THE SMART CITY}

How can cities become 'smarter' and do they necessarily become more resilient? Are the two terms, that recently gain popularity and have been much discussed among urbanists,

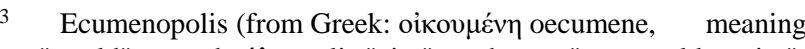
"world", and $\pi$ ó $\lambda \iota s$ polis "city", thus "a world city"; pl. ecumenopolises or ecumenopoleis) is the hypothetical concept of a planet wide city. The word was invented in 1967 by the Greek city planner Constantinos Apostolou Doxiadis to represent the idea that in the future urban areas and megalopolises would eventually fuse and there would be a single continuous worldwide city as a progression from the current urbanization, population growth, transport, and human networks. academics, government, and stake holders necessarily connected and what is the difference between them?

By definition a resilient city has conventionally been defined as the "measurable ability of any urban system, with its inhabitants, to maintain continuity through all shocks and stresses, while positively adapting and transforming towards sustainability (Mariani, 2017). These disasters can be caused by climate changes, but can also have economic or social roots. The resilience of cities is measured in well-functioning communication and networking between four areas: economy, society, government, and environment (OECD, 2021). The first appearance of the concept of resilient cities dates back to 2002, but it was not until the early 2010s that the topic became popular; as Prof van der Bosch suggests the frequency of Google search on the matter (of resilient cities) started to boom in 2012 (Van der Bosch, 2017). The concept of the resilient city was further developed and applied in practice after large-scale hazards like the hurricanes Katrina (2005) and Sandy (2012), both in the United States. But how city resilience can be actually measured? The resilient city framework developed by Arup gives the base for the calculation of indicators of city's resilience in different aspects. This helps the city's authorities to develop a strategy for improvement of the weak points. By 2017, thirty cities around the world have calculated their resilience and published the reports including improvement strategies to be undertaken within the next ten years (Van der Bosch, 2017).

The concept of a Smart city seems very contemporary and the birthdate of it is unknown, but during the 1960s and 1970s cities were using technology to gather, interpret and visualize data. In 1974 in Los Angeles "A Cluster Analysis of Los Angeles" report used cluster analysis and infrared aerial photography to gather data, produce reports on neighbourhood demographics and housing quality to help direct resources to avoid illness and tackle poverty (Vallianatos, 2015). To bring Smart city action into the future, the next milestone happens in Amsterdam in the 1990s where the city created the first virtual 'digital city' (Verdict, 2020). This idea had its breakthrough during the economic crisis in the mid-2000s when large technology companies such as Cisco, IBM, Siemens, Philips use the opportunity to introduce themselves as Smart city experts and improve their business (Van der Bosch, 2017). As European Commission defines, smart cities improve traditional networks and services using "digital and telecommunication technologies for the benefit of its inhabitants and business" (European Commission, 2021).

Applying concepts of resilience and Smart city technologies in urban areas will help to reduce emissions and better manage natural resources; improve urban transport networks, water supply and waste disposal facilities, and upgrade energy efficiency in buildings. "It also means a more interactive and responsive city administration, safer public spaces and meeting the needs of an aging population" (European Commission, 2021).

Smart cities are related to city resilience, but the roots of these notions are quite different. As already mentioned, the concept of the Smart city is assuredly related to the latest technological achievements and digitalization, and on many levels the complexity of daily human needs are included in these projects, from public sector officials to small businesses, large industries to researchers, etc. Even the introduction of small-scale projects can contribute to making the city smarter and will help the city become more resilient for future challenges. 


\section{METHODOLOGY}

Conducting a research for this paper, many literature sources were reviewed relating to the concepts and parameters of smart city and resilient city. Furthermore, different examples on digitalisation of cities (mostly across the European Union) were collected and compared. Finally, some of them were chosen for introduction into this text. Those examples are representing different aspects of smart city interventions and could be considered for implementation in Sarajevo, as well. The second part of this research relates to Sarajevo and presents several steps in the implementation of smart city technologies. The presented examples from Sarajevo mostly contribute to the improvement of mobility and city environment yet still lack the digital character of the smart city idea.

\section{ADOPTION OF SMART CITY TECHNOLOGIES}

Examples of Smart city technologies have been adopted and implemented around the Globe to improve and ease the life of large cities inhabitants. Western European cities such as Amsterdam, Madrid, Barcelona, and many more are actively pursuing Smart city strategies as well as cities such as New York, Singapore, Seoul, Calgary, and many others globally.

The scope of the Smart city technologies varies greatly and the projects cover a large spectrum of improvements of city life. From reducing traffic, saving energy and improving public safety, to smart energy meters for many homes with an incentive to provide to those that actively reduce energy consumption as cased in Amsterdam.

By investing (new technologies) in public places, smart cities can become the places people want to spend more time in. The city of Barcelona is a good example of pioneering smart technologies by implementing a network of fiber optics through the city and providing free high-speed WiFi that supports the IoT. Barcelona's development towards a Smart city began over 30 years ago when the city installed fiber optic cables to connect two municipal buildings. By integrating water, lighting, and parking, the city saved 75 million euros for the city funds and created 47.000 new jobs in the Smart city sector (Ellsmoore, 2019). Voted European Capital of Innovation in 2014, Barcelona is a metropolitan hub with a long tradition of industry and entrepreneurship and has among others, implemented things such as a new bus network based on data analysis of the most common traffic flows in the city, utilizing primarily vertical, horizontal, and diagonal routes with a number of interchanges. Integration of multiple Smart city technologies can be seen through the implementation of smart traffic lights as buses run on routes designed to optimize the number of green lights.

In addition, where an emergency is reported in the city, the approximate route of the emergency vehicle is entered into the traffic light system, setting all the lights to green as the vehicle approaches through a mix of GPS and traffic management software, allowing emergency services to reach the incident without delay (European Commission Publication, 2017). Among hundreds of the Smart city initiatives, the inhabitants of Barcelona can now test the network of sensors that will collect and give information on the flow of people and bicycles along the city's biggest roads and arteries, the decibel levels on each street, the temperature of each neighbourhood and the quality of the air.

China which has ten cities with a population of more than 10 million inhabitants, has pushed forward with a variety of smart technologies, some that raise privacy risks and interfere with confidentiality. Piva suggests that there are more than 300
Smart city technologies to be implemented into the Chinese cities where face recognition is one of them. This collides with privacy policies and becomes an issue. One such project is face recognition as a valid proof of a bus ticket purchase (Anthopoulos, 2019).

But the Smart city technology is not exclusive to the large megacities even if these vast urban areas benefit from them most. SC technologies are applied in smaller and small European cities improving the quality of life and use of the space of the cities inhabitants.

The Spanish city of San Sebastian has less than 200.000 inhabitants and was the European Capital of Culture in 2016. Its commitment to science, technology, economic development, sustainability, and culture is echoed in the Smart city strategies that are reflected in the use of energy efficiency in the buildings, district heating and cooling, and electric and hybrid bus lines among other things. District heating and cooling systems will alone give a reduction of $35 \%$ in primary energy consumption, where $90 \%$ of this energy is renewable, and $85 \%$ reduction of $\mathrm{CO} 2$ emissions, when the system is fired by a power plant with $7400 \mathrm{~kW}$ of power and two $1400 \mathrm{~kW}$ biomass boilers (European Commission Publication, 2017).

\section{IMPLEMENTATION OF SMART CITY TECHNOLOGIES IN SARAJEVO}

The city of Sarajevo is the capital of Bosnia and Herzegovina and the Federation of Bosnia and Herzegovina ${ }^{4}$. It is also the seat of the Sarajevo Canton and as such functions as a local government unit. Sarajevo is a city with high air pollution ${ }^{5}$ caused less by the industry but more due to the geographic position of the city (established and developing in the Sarajevo valley surrounded by high mountains). The air pollution is particularly high during the winter months when the whole city suffers from smog (Figure 1). The exhausts from heating as well as heavy traffic caused by old cars increase the maximum acceptable amount of PM10 particles in the air, which generally have a large number of exceedances during the year.

4 The state of Bosnia and Herzegovina consists of two entities (Federation of Bosnia and Herzegovina and Republica Srpska) and the Brcko District. The Federation of Bosnia and Herzegovina is an entity consisting of ten cantons that are further administratively divided into municipalities. One of the cantons is also Sarajevo Canton that consists of 9 municipalities, of which 4 comprise the city of Sarajevo.

5 Air quality can be monitored here https://zrak.ekoakcija.org/sarajevo and here http://www.fhmzbih.gov.ba/latinica/ZRAK/AQI-satne.php 


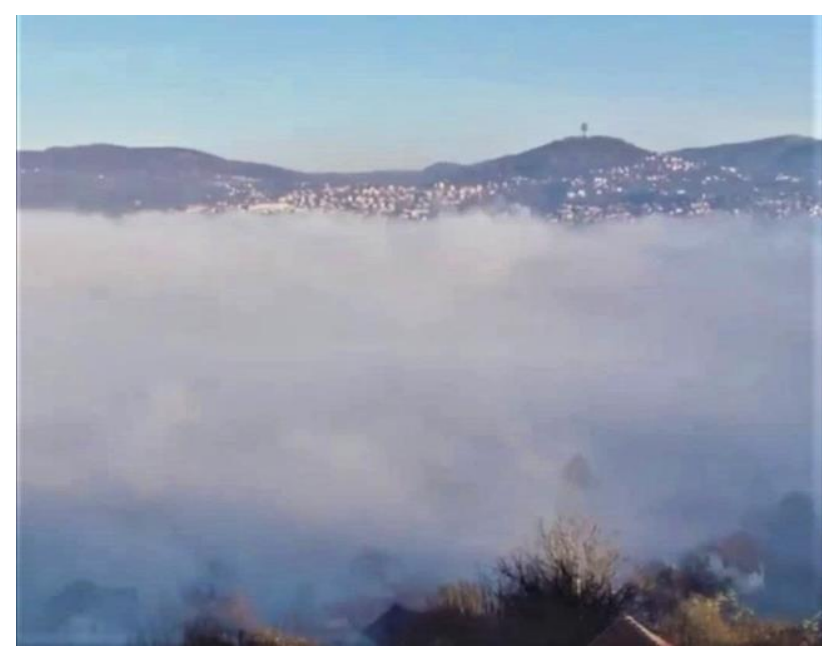

Figure 1. Sarajevo under smog during the winter months.

In 2010 the mayor of Sarajevo joined the Covenant of Mayors ${ }^{6}$ and signed the Agreement that binds them to commit themselves to the implementation of numerous energy efficiency measures that will ultimately reduce $\mathrm{CO} 2$ emissions in their cities by more than $20 \%$ by the year 2020. This is required by the 2007 European Energy Policy Proposal.

Action Plan for sustainable energy development of Sarajevo was defined in 2011 and proposes different actions to be implemented by 2020 with the aim to improve the energy efficiency in the city and its wider area.

These projects cover all private and public buildings owned by the City as well as public transportation and lighting.

Even though, not still a member of the EU, the country, at its highest level, has adopted many legislations to match the EU requirements. One such law tailored following the EU norms and directives is the Law on energy efficiency of the Federation of Bosnia and Herzegovina. Among other things, this Law regulates energy efficiency in buildings.

Based on the above-mentioned Law, a substantial number of projects on thermal insulation of buildings and upgrading of heating systems in Sarajevo Canton have been implemented. From 2007 to 2012, the Ministry of Housing Policy of Sarajevo Canton implemented a pilot project improving energy efficiency in residential buildings in one of Sarajevo's municipalities (Figure 2). This project included 11 residential buildings with a collective heating system and 6 smaller residential buildings with an individual heating system (Zavitan, 2016). Other municipalities have followed this example as well. In 2020, the same ministry reserved the budget for the improvement of

6 At the end of January 2008, the European Commission launched an initiative to connect the major energy-conscious European cities into a permanent network with the aim of exchanging experiences in application effective measures to improve the energy efficiency of urban areas. Covenant of Mayors is the response of advanced European cities to the challenges of global climate change, and at the same time, the first and most ambitious initiative of the European Commission aimed directly at active involvement and continuous participation of city administrations and citizens themselves in the fight against global warming. Until June 2011 the Agreement has been signed by over 2600 mayors of different European cities (mostly in Spain and Italy). Besides Sarajevo, in Bosnia and Herzegovina, this Agreement also joined the cities of Banja Luka, Bijeljina, Prijedor and Tuzla. (https://mpz.ks.gov.ba/) energy efficiency on 53 individual buildings, and one building of collective housing in four different municipalities.

The total number of thermally insulated public and residential buildings in Sarajevo is not known, as a collective database does not exist.

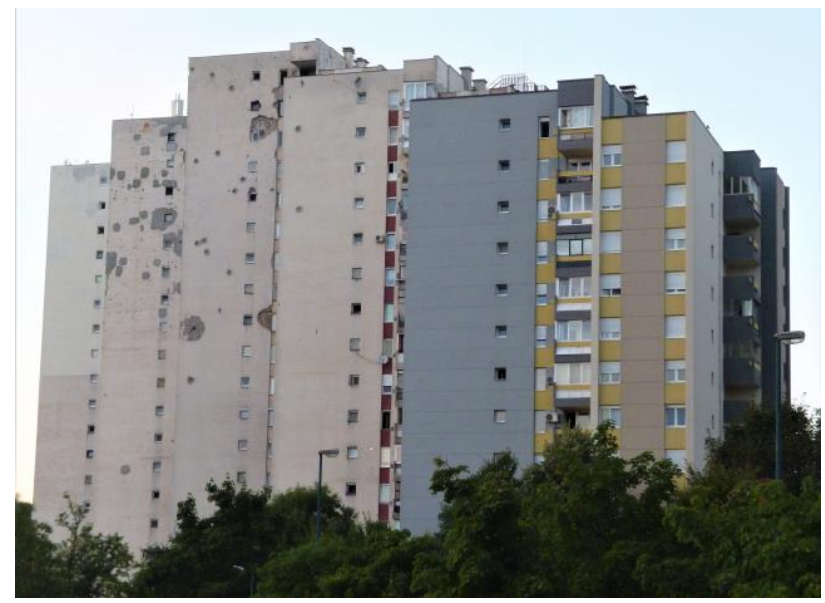

Figure 2. One of the buildings in the municipality Novi Grad that was refurbished according to standards of energy efficiency

(left part of the building damaged during the war, right part refurbished).

This positive trend should continue together with projects that would improve heating systems, as methods of heating vary and are one of the strongest air pollutants. In particular, the lowincome individual households are problematic as many of those do not have adequate thermal insulation if any, and often use low-quality coal or coal with sulfur for heating. The best heating solution could be achieved by the implementation of the project of the remote heating system from the thermal power plant in Kakanj, ca. 50km north-west from Sarajevo. Several studies have been done on this topic (the last one in 2016) but until now the implementation of this project is still on hold, mostly due to financial reasons.

Other smaller steps in the improvement of air quality have been done in the area traffic pollution. The city has one main tram line operating longitudinally connecting the city in the east-west direction as well as the electrically operated trolley-buses. However, to reach remote, elevated parts of the city, buses and mini-busses are needed and they are mostly using petrol. In 2019 , some of the 'regular' buses have been exchanged for gas operating ones.

"In order to reduce the amount of harmful exhaust gases that negatively affect the environment in the Sarajevo Canton, especially in the winter, a decision was made to continuously change buses running on city lines with environmentallyfriendly vehicles. It turned out that gas-operated buses, in addition to environmental friendliness, are more modern, more comfortable, and have lower noise intensity." (https://energetika.ba/)

In 2016, the city introduced a project of bike rentals (Nextbike) already known in many other European countries. The company positioned several renting stations across the city and people rent bikes using an easy mobile application. Since September 2020 , it is also possible to rent electrical romobils. This definitely makes transportation in the city easier and cleaner and is a good solution in the time of Corona pandemic where people prefer to rent bikes or romobils over public transportation. One of the project initiators says that "this is an environmentally 
friendly mode of transport, fast, easy, and reduces traffic congestion, which is a big problem of Sarajevo" (Klix, 2020). The current mayor also supports this new project stating that this mode of transport perfectly fits into the Smart city strategy the authorities are currently developing, together with the green city platform they are working on.

Another recently launched (01.01.2021) important project "Urban LED" realized by the Environmental Protection Fund of FBiH with the help of UNDP is related to Waste management information system on the level of Federation. All public and private subjects that manage, collect, recycle, and produce waste as a result of their work and production process, should register and submit data in the Waste Management Information System of FBiH. This will help to network these subjects, as well as to correctly manage, recycle and dispose of waste (Fond za zastitu okolisa, 2020).

The introduced projects and many others represent small steps in raising the quality of life in Sarajevo by improving city traffic and reducing $\mathrm{CO} 2$ emissions.

Compared to the Smart city technologies applied in other European countries (such as seen in examples introduced in this paper) Sarajevo needs more digitalization which will help to manage energy consumption, traffic flow and pollution, waste and water, etc.

\section{CONCLUSION}

Generally speaking, City is a large system of a variety of functions that come together under the unique history that is located in a specific social and environmental context. For a City to be successful and prosperous, these "functions" should work well together by overcoming problems in the City. The concept of a Smart city does this and as the world's population gathers in cities, making them larger the "smartness" becomes more important as it effectively optimizes the use of the resources.

Sarajevo has successfully started implementing Smart city concepts, but there is still plenty of room for improvement. The main obstacle in the realization of existing project plans is finances, but also a very complex administrative structure. So far, most of the implemented projects have been realized with the help of foreign organizations such as UNDP or foreign governments through their Embassies.

There are many EU funds for which the cities' authorities in Bosnia and Herzegovina can apply in order to fulfil their Action Plans. Diversity of projects could be implemented in the near future such as digitalization of traffic network to improve traffic flow, changing all busses and mini-busses to the gas-operating mode, installing solar collectors on major public buildings and collective housing, advanced use of green roofs, finally realizing the remote heating project, starting 'sharing cars' projects, and many more. The authorities must engage more actively in the implementation of such projects that would improve the quality of life in a post-war Sarajevo that has been rapidly extending. This process must necessarily include the local communities and citizens in general as well as economic entities. Only in that way Sarajevo can be reshaped in the future not only to a Smart city but also to a resilient one that can resist future ecological and social challenges.

Any smart technology implemented in a City that assists and improves cities' inhabitant's daily tasks is making that city a Smart city. Admittedly, the more new technologies are applied, the easier daily life becomes. Examples shown in this paper give us a clear path for the future of the City as the population increases and the natural resources become more and more limited. Smart technologies are the only solution for the City of the future, the ecumenopolis.

\section{REFERENCES}

Anthopoulos, L. Ed., 'Smart City Emergence - cases from around the world' Elsevier 2019, pp. 21-22

Caves, R. W. 'Encyclopedia of the City', Routledge 2004, pp. 281

Clark, G. Moonen, T. Nunly, J. 'The Story of Your City: Europe and its Urban Development, 1970 to 2020' European Investment Bank, 2018, [online]. Available at: https://www.eib.org/en/essays/the-story-of-your-city (Accessed: 11 February 2021)

Cohen, B. 'Urbanisation, city growth and new United Nations development agenda', Corenrstone, Volume 3, Issue 2, Summer 2015, pp.4-7

Deakin, M., Al Waer, H., 'From Intelligent to Smart Cities', Journal of Intelligent Buildings International: From Intelligent Cities to Smart Cities, 2011, pp. 140-152.

Ellsmoore, J., 'Smart Cities: The Future of Urban Development', Forbes, 2019, [online]. Available at: https://www.forbes.com/sites/jamesellsmoor/2019/05/19/smartcities-the-future-of-urban-development/?sh=789c9fdd2f90

(Accessed: 12 February 2021)

European Commission, 2021, 'Smart Cities' [online]. https://ec.europa.eu/info/eu-regional-and-urbandevelopment/topics/cities-and-urban-development/cityinitiatives/smart-cities_en (Accessed: 12 February 2021)

European Commission Publication, 2017, 'The making of smart cities: Best practices across Europe', [online]. https://smartcities-marketplace.ec.europa.eu/insights/publications/makingsmart-city-best-practices-across-europe (Accessed: 12 February 2021)

Fond za zastitu okolisa, 2020, 'Uspostavljen informacioni sistem upravljanja otpadom Federacije BiH', , [online]. https://fzofbih.org.ba/?utm_source=Klix.ba\&utm_medium=Cla nak, (Accessed: 19 February 2021)

https://ajuntament.barcelona.cat/digital/en (Accessed: 12 February 2021)

https://amsterdamsmartcity.com/ [online]. (Accessed: 11 February 2021)

https://energetika.ba/centrotrans-za-gradski-prevoz-u-sarajevunabavio-sest-novih-autobusa-na-plin/, 2018, [online]. (Accessed: 18 February 2021)

https://mpz.ks.gov.ba/aktuelno/novosti-iz-vlade/pocinjeutopljavanje-53-individualna-objekta-u-kantonu-sarajevo 2020, [online]. (Accessed: 18 February 2021)

Klix, 2020, 'U Sarajevu ćete od ponedjeljka romobil na struju moći unajmiti preko mobitela', [online]. https://www.klix.ba/vijesti/bih/u-sarajevu-cete-od-ponedjeljkaromobil-na-struju-moci-unajmiti-preko-mobitela/200910058,

(Accessed: 19 February 2021) 
Mariani, L., 'What is urban resilience?', Urban resilience, 2017, [online]. https://urbanresiliencehub.org/ (Accessed: 12 February 2021)

McLaren, D., Agyeman, J. 'Sharing Cities: A Case for Truly Smart and Sustainable Cities’, MIT Press 2015, pp. 199-246

OECD, 2021, 'Measuring Cities Resiliance', [online]. https://www.oecd.org/regional/resilient-cities.htm (Accessed: 10 February 2021)

Vallianatos, M., 'Uncovering the Early History of "Big Data" and the "Smart City" in Los Angeles', Boom Califorina, 2015, [online]. https://boomcalifornia.org/2015/06/16/uncovering-theearly-history-of-big-data-and-the-smart-city-in-la/ (Accessed: 12 February 2021)

Van der Bosch, H., 'Smart cities or resilient cities. Does it make any difference?', Smart City Hub, 2017, [online].

https://smartcityhub.com/collaborative-city/smart-citiesresilient-cities-make-difference/ (Accessed: 10 February 2021)

Verdict, 2020, 'History of smart cities: Timeline', [online]. https://www.verdict.co.uk/smart-cities-timeline/(Accessed: 10 February 2021)

Zavitan, M., 'Renesansa: Utopljavanje zgrada u Sarajevu - šta podrazumijeva i koje su koristi za građane i okolinu', 2016, [online]. (https://radiosarajevo.ba/vijesti/lokalneteme/enesansa-utopljavanje-zgrada-u-sarajevu-stapodrazumijeva-i-koje-su-koristi-za-gradane-i-okolinu/220985) (Accessed: 18 February 2021) 